\title{
Unusual Presentation of COVID-19: Encephalitis and Syndrome of Inappropriate Anti-Diuretic Hormone Secretion
}

\author{
Maresca Andrea1,2, Mongiardi Christian², Montalbetti Lorenzo², Dentali Francesco ${ }^{1,2}$, \\ Ageno Walter, ${ }^{1,2}$, Mauri Marco',2, Baj Andreina ${ }^{1,2}$, Grandi Anna Maria ${ }^{1,2}$, Grossi Paolo, \\ Dalla Gasperina Daniela ${ }^{1,2}$, Zerba Francesco ${ }^{1}$, Sessa Aurelio ${ }^{1,2}$, Guasti Luigina ${ }^{1,2 *}$
}

${ }^{1}$ University of Insubria, Varese, Italy

${ }^{2}$ ASST-Settelaghi, Varese, Italy

Email: ^Luigina.guasti@uninsubria.it

How to cite this paper: Andrea, M., Christian, M., Lorenzo, M., Francesco, D., Walter, A., Marco, M., Andreina, B., Maria, G.A., Paolo, G., Daniela, D.G., Francesco, Z., Aurelio, S. and Luigina, G. (2020) Unusual Presentation of COVID-19: Encephalitis and Syndrome of Inappropriate Anti-Diuretic Hormone Secretion. International Journal of Clinical Medicine, 11, 559-564.

https://doi.org/10.4236/ijcm.2020.1110048

Received: August 10, 2020

Accepted: October 18, 2020

Published: October 21, 2020

Copyright $\odot 2020$ by author(s) and Scientific Research Publishing Inc. This work is licensed under the Creative Commons Attribution International License (CC BY 4.0).

http://creativecommons.org/licenses/by/4.0/

\begin{abstract}
COVID-19 is a new challenge in clinical medicine. Although typical presentations include fever and pneumonia, we describe a case of COVID-19 presenting with neurological symptoms of encephalitis and infectious-related syndrome of inappropriate anti-diuretic hormone secretion. Because of the epidemic health problems, it is crucial to identify these patients as early as possible to follow the isolation procedures. We suggest that unclear neurological clinical presentations of patients should be considered for COVID-19.
\end{abstract}

\section{Keywords}

COVID-19, SARS-Cov-2, Encephalitis, Syndrome of Inappropriate Anti-Diuretic Hormone, Isolation Procedures

\section{Introduction}

Coronavirus Disease (COVID-19) has spread as a world pandemic in the last few months. Since this epidemic is sustained by a new strain of coronavirus (Severe Acute Respiratory Syndrome Coronavirus-2: SARS-CoV-2), new aspects of this disease are emerging.

The first clinical descriptions of the disease point to lung disease often leading to pulmonary failure [1] [2]. However, neurotropic properties have been shown for coronavirus and SARS-Cov-2 [3] and neurological manifestations such as loss of smell have been described [4]. 


\section{Clinical Case}

Among atypical presentations of COVID-19, we describe here for the first time a neurological presentation with encephalitis and syndrome of inappropriate anti-diuretic hormone secretion (SIADH).

The patient, Ms. P.A., female, 79 years old, was admitted on March 7th, 2020 to the University Hospital of Varese, during the epidemic phase of SARS-CoV-2 in Lombardy Region, Italy.

At admission in the emergency department, she presented with neurological symptoms suggesting encephalitis (confusion, somnolence, psychomotor retardation, cephalea). Five to 7 days before admission to the hospital the patient reported gastrointestinal symptoms, with vomit and diarrhea, followed by constipation. In her medical history, the patient referred rheumatoid arthritis treated with hydroxychloroquine sulfate $(200 \mathrm{mg} /$ day $)$ and low dose steroid treatment (prednisone $5 \mathrm{mg} /$ day).

At the clinical evaluation, no fever, no dyspnea and no cought were reported. Laboratory tests revealed severe hyponatremia $(118 \mathrm{mEq} / \mathrm{L}$; normal range: 136 $150 \mathrm{mEq} / \mathrm{L})$ and normal values of $\mathrm{C}$ reactive Protein $(1.6 \mathrm{mg} / \mathrm{L}$; normal range: $0.0-5.0 \mathrm{mg} / \mathrm{L}$ ) and lactate dehydrogenase (235 U/L; normal range: $130-240$ $\mathrm{U} / \mathrm{L}$ ), and no lymphopenia.

After submitting the patient to brain CT scan (Figure 1: non-specific diffuse cerebral atrophy), the neurologist suggested the execution of a lumbar puncture. Cerebrospinal fluid (CSF) analysis showed normal findings: glucose $49 \mathrm{mg} / \mathrm{dL}$, proteins $61 \mathrm{mg} / \mathrm{dL}$; $<15$ cells /field, negative search for cells and bacteria at microscopy. A search for polymerase chain reaction for Herpes Simplex Virus (HSV) 1 and HSV-2 was conducted on the CSF sample. At electroencephalography triphasic waves were interpreted as non-specific findings and in relation to dysmetabolic changes. At supine chest X Ray there were no signs of lung parenchymal disease (Figure 2(a)).

The patient was then transferred on March 10th to the Internal Medicine ward dedicated to non-COVID patients. She progressively continued the correction of hyponatremia, and SIADH was diagnosed [5] based on decreased effective osmolality of the extracellular fluid ( $\mathrm{P}_{\text {osm }}$ : $265 \mathrm{mOsmol} / \mathrm{Kg} \mathrm{H}_{2} \mathrm{O}$ ), inappropriate urinary concentration ( $\mathrm{U}_{\text {osm: }} 377 \mathrm{mOsmol} / \mathrm{KgH}_{2} \mathrm{O}$ ), and elevated urinary $\mathrm{Na}$ excretion (189 mmol/24h). A total body CT scan was prescribed for the clinical suspect of a malignant-associated SIADH. The patient was started on acyclovir therapy while waiting for the HSV-DNA result. To further investigate whether a sub-occluding fecaloma was the cause of the mild abdominal pain and constipation reported the days before admission, a rectal exploration was conducted with the finding of malodorous, curry-colored feces.

On March 11th and 12th, hyponatremia was almost completely corrected (130 $\mathrm{mEq} / \mathrm{L}$ ) with a progressive, slow improvement of neurological symptoms, but recovery was incomplete and she was still partially inappropriately confused (to be noted that the patient was fully active and was able of caring the whole family before hospital admission). 


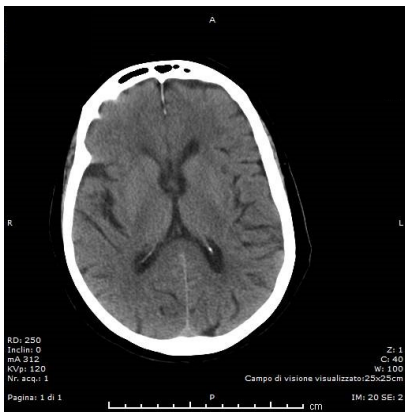

(a)

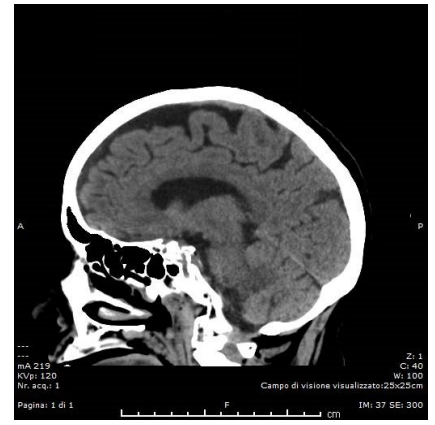

(b)

Figure 1. Brain CT scan. (a) and (b) show non-specific diffuse cortical atrophy at brain CT scan.

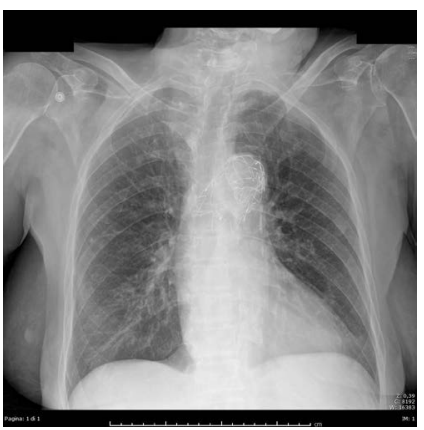

(a)

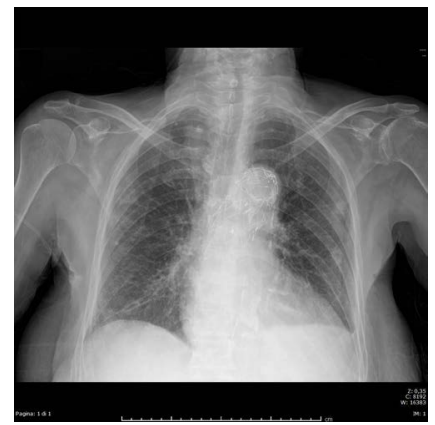

(b)

Figure 2. Chest X Rays at admission and during pneumonia. (a) shows a normal chest X Ray at admission to the hospital (patient in supine position), in the presence of only neurological symptoms and (b) (patient in sitting position) shows mild lung peripheral parenchymal infiltrate, in the presence of mild classical COVID-related symptoms adding to the neurological manifestations. 
The total body CT scan was performed on March, 13th and showed normal findings; in particular no malignancies, no pneumonia or lung diseases. Testing for HSV was negative and acyclovir treatment was stopped.

On March 14th she presented fever (temperature $38^{\circ}$ Celsius) and light cough and, therefore, she performed a nasopharyngeal swab for SARS-CoV-2 which resulted positive (for methods see supplemental material). The CSF obtained 7 days prior to the occurrence of fever in the suspect of neurological disturbances other than COVID-19, was then tested for SARS-CoV-2 with negative results (for methods see supplemental material).

The patient was then moved to a dedicated COVID department where she developed mild signs of COVID-19-related pneumonia (mild dyspnea and $\mathrm{O}_{2}$ desaturation at pulse oximeter; at chest X Ray (Figure 2(b)): mild peripheral parenchymal infiltrate), and was treated with lopinavir/ritonavir, hydroxychloroquine sulfate (200 $\mathrm{mg}$ twice/day), antibiotics (piperacillin/tazobactam) and mild non-invasive $\mathrm{O}_{2}$ therapy $(2 \mathrm{~L} / \mathrm{min})$. In 15 days she recovered completely from COVID-19 and from the neurological symptoms which caused the admission to hospital. No fluid restriction was needed and no problems about hydro-electrolytic balance persisted during recovery and she was dismissed after performing 2 negative nasopharyngeal swabs.

Informed consent was obtained from the patient to report the case.

\section{Discussion}

The unusual case of COVID-19 described here showed an initial clinical presentation with exclusive neurological symptoms and an infectious-related SIADH, followed by fever and dyspnea after few days. The oddity of this case is increased by the fact that the patient was already treated (because of rheumatoid arthritis) with drugs used for COVID-19 treatment (hydroxychloroquine and steroids) before admission and before developing more classical symptoms and signs of the SARS-CoV-2-related pneumonia. Possibly, this treatment may have masked for a few days the developing of a COVID-19-related typical lung disease and may have interfered with the finding of SARS-CoV-2 in the cerebrospinal fluid.

Ye et al. showed encephalitis as an additional manifestation of COVID-19 coming with the classical symptoms [6] and Poyiadji et al. reported images of acute hemorrhagic necrotizing encephalopathy associated with COVID-19 [7]. Our report adds to the one from Moriguchi et al. [8] who described a meningitis/encephalitis associated with SARS-CoV-2 in a case of convulsion accompanied by unconsciousness as presenting symptoms.

Preventive measures against pandemics are based on a prompt recognition of cases that can lead to patient's isolation, the only measure to contrast the propagation of infection. The attempt to make an early diagnose of COVID-19 is a crucial step to avoid contaminations of non-COVID medical departments. The unusual occurrence of early neurological symptoms as first manifestation of SARS-CoV-2 infection suggests that health professionals should be advised to 
consider COVID-19 in patients showing unclear clinical presentations of complex neurological symptoms.

\section{Conflicts of Interest}

The authors declare no conflicts of interest regarding the publication of this paper.

\section{References}

[1] Guan, W.J., Ni, Z.Y., Hu, Y., Liang, W.H., Ou, C.Q., He, J.X., Liu, L., Shan, H., Lei, C.L., Hui, D.S.C., Du, B., Li, L.J., Zeng, G., Yuen, K.Y., Chen, R.C., Tang, C.L., Wang, T., Chen, P.Y., Xiang, J., Li, S.Y., Wang, J.L., Liang, Z.J., Peng, Y.X., Wei, L., Liu, Y., Hu, Y.H., Peng, P., Wang, J.M., Liu, J.Y., Chen, Z., Li, G., Zheng, Z.J., Qiu, S.Q., Luo, J., Ye, C.J., Zhu, S.Y., Zhong, N.S. China Medical Treatment Expert Group for Covid-19. (2020) Clinical Characteristics of Coronavirus Disease 2019 in China. The New England Journal of Medicine, 382, 1708-1720. https://doi.org/10.1056/NEJMoa2002032

[2] Chen, N., Zhou, M., Dong, X., Qu, J., Gong, F., Han, Y., Qiu, Y., Wang, J., Liu, Y., Wei, Y., Xia, J., Yu, T., Zhang, X. and Zhang, L. (2020) Epidemiological and Clinical Characteristics of 99 Cases of 2019 Novel Coronavirus Pneumonia in Wuhan, China: A Descriptive Study. The Lancet, 395, 507-513. https://doi.org/10.1016/S0140-6736(20)30211-7

[3] Wu, Y., Xu, X., Chen, Z., Duan, J., Hashimoto, K., Yang, L., Liu, C. and Yang, C. (2020) Nervous System Involvement after Infection with COVID-19 and Other Coronaviruses. Brain, Behavior, and Immunity, 87, 18-22. https://doi.org/10.1016/j.bbi.2020.03.031

[4] Giacomelli, A., Pezzati, L., Conti, F., Bernacchia, D., Siano, M., Oreni, L., Rusconi, S., Gervasoni, C., Ridolfo, A.L., Rizzardini, G., Antinori, S. and Galli, M. (2020) Self-Reported Olfactory and Taste Disorders in Patients with Severe Acute Respiratory Coronavirus 2 Infection: A Cross-sectional Study. Clinical Infectious Diseases, 71, 889-890.https://doi.org/10.1093/cid/ciaa330

[5] Verbalis, J.G., Goldsmith, S.R., Greenberg, A., Korzelius, C., Schrier, R.W., Sterns R.H. and Thompson, C.J. (2013) Diagnosis, Evaluation, and Treatment of Hyponatremia: Expert Panel Recommendations. The American Journal of Medicine, 126(Suppl 1), S1-42. https://doi.org/10.1016/j.amimed.2013.07.006

[6] Ye, M., Ren, Y. and Lv, T. (2020) Encephalitis as a Clinical Manifestation of COVID-19. Brain, Behavior, and Immunity, 88, 945-946.

https://doi.org/10.1016/j.bbi.2020.04.017

[7] Poyiadji, N., Shahin, G., Noujaim, D., Stone, M., Patel, S. and Griffith, B. (2020) COVID-19-Associated Acute Hemorrhagic Necrotizing Encephalopathy: Imaging Features. Radiology, 296, E119-E120. https://doi.org/10.1148/radiol.2020201187

[8] Moriguchi, T., Harii, N., Goto, J., Harada, D., Sugawara, H., Takamino, J., Ueno, M., Sakata, H., Kondo, K., Myose, N., Nakao, A., Takeda, M., Haro, H., Inoue, O., Suzuki-Inoue, K., Kubokawa, K., Ogihara, S., Sasaki, T., Kinouchi, H., Kojin, H., Ito, M., Onishi, H., Shimizu, T., Sasaki, Y., Enomoto, N., Ishihara, H., Furuya, S., Yamamoto, T. and Shimada, S. (2020) A First Case of Meningitis/Encephalitis Associated with SARS-Coronavirus-2. International Journal of Infectious Diseases Impact, 94, 55-58. https://doi.org/10.1016/j.ijid.2020.03.062 


\section{Supplemental Material}

\section{METHODS: Evaluation of SARS-CoV-2 in biological specimens Nasopharyngeal swab}

After virus inactivation for 1 minute at $90^{\circ} \mathrm{C}$, RNA extraction from the nasopharyngeal swab is performed with Abbott mSample Preparation System (Promega corporation) and an automated extraction system (Extraction m2000SP, Abbott Molecular). Obtained RNA is amplified with GeneFinder COVID-19 plus RealAmp PCR kit (ELITechGroup), one step Reverse Transcription Real-Time PCR system targeting RdRp, E, and N genes.

\section{Cerebrospinal fluid}

Cerebrospinal fluid was subjected to RNA extraction by QIAmp Viral RNA mini kit (Qiagen) and eluted in $60 \mu \mathrm{l}$. One step rRT-PCR was performed using Luna Universal qPCR Master Mix (New England BioLab) with primers targeting the 5'UTR region of SARS-CoV-2. A nested PCR, after retrotranscription with Superscript IV Reverse Transcriptase (Thermo Fisher Scientific) was used to amplify ORF1ab, S, E, and $\mathrm{N}$ regions. All tested regions gave a negative result. 